Recibido: 18-septiembre-2013

Aceptado: 07-octubre-2013

\title{
MAQUIAVELO A 500 AÑOS DE EL PRÍNCIPE
}

\section{JULIO ECHEVERRÍA}

Facultad de Jurisprudencia Ciencias Políticas y Sociales Universidad Central del Ecuador 


\section{RESUMEN}

El autor en este ensayo recupera las posturas centrales de la obra del pensador florentino Nicolás Maquiavelo, a propósito de la celebración de los 500 años de la aparición de su célebre libro El Príncipe. En la discusión de la ciencia política, Maquiavelo aparece como su fundador e inspirador principal; desde entonces se delinean sus rasgos fundamentales; el estudio de la política es el estudio de la conducta humana atravesada por la lógica del poder. La modernidad de Maquiavelo, -nos indica el autor- está en su postura secular en un contexto de fuertes tensiones religiosas como fueron las que se desataron en el contexto del renacimiento italiano, del cual es seguramente uno de sus máximos exponentes; la política deja de ser la instrumentación en la tierra de un poder sobrenatural y pasa a ser la construcción de una obra humana por excelencia. Tal cual acontece con la ciencia natural y experimental de Telesio o de Galileo; de igual forma, la ciencia de Maquiavelo es la experimentación de la mejor forma de organización de las relaciones interhumanas. En su forma germinal, la política es guerra y enfrentamiento. El Príncipe debe estar en capacidad de construir su poder mediante la anulación de los otros poderes; política y diplomacia se presentan como dos caras de una misma moneda, como arte de arreglar los conflictos o de preparar las mejores condiciones para el enfrentamiento y para la guerra; una funcionalidad alterna que tiene que ver con la presentación de los medios más adecuados para conseguir, mantener y reproducir el poder político. Una combinación de pragmatismo y visión estratégica que Maquiavelo no encontró en los líderes de su tiempo; la tragedia de Maquiavelo no consistió solamente en su aislamiento de las lógicas del poder, en su dificultad por incidir decisivamente en el curso político de la Florencia de su época, su mayor tragedia residió en la indiferencia con la cual fue acogido su opúsculo De principatibus por Lorenzo de Medici, a quien estaba dedicado y en quien confiaba la tarea del resurgimiento de Italia; indiferencia que contrastará con la aceptación que su obra tendrá en la posteridad, una aceptación enormemente polémica, de elogio y rechazo, pero en ningún caso de indiferencia.

\section{ABSTRACT}

The author in this essay recovers central tenets of the Florentine thinker Niccolo Machiavelli's work in the celebration of the 500th anniversary of the appearance of his famous book The Prince. In the discussion of political science, Machiavelli appears as its founder and principal inspiring and since then outlines its main features, the study of politics is the study of human behavior crossed by the logic of power. The modernity of Machiavelli, the author tells us in his secular stance in the context of religious tensions which were triggered in the context of the Italian Renaissance, that is certainly he is one of its greatest exponents, the policy ceases be the implementation on the ground of supernatural power and becomes building a quintessential human endeavor. As happes with natural science or Telesio experimental Galileo, Machiavelli science experimentation is the best way of organizing human relationships. In its germ, politics is war and confrontation. The Prince should be able to build his power by canceling the other branches; politics and diplomacy are presented as two sides of the same coin, as conflict art of arranging or preparing the best conditions for confrontation and war alternating functionality. That has to do with the presentation of the most appropriate means to achieve, maintain and reproduce political power. A combination of pragmatism and strategic vision that Machiavelli did not find in the leaders of his time, the tragedy of Machiavelli did not consist only in the isolation of logic from the power, in its difficulty to decisively influence the political course of the Florence of his time, its greatest tragedy lay in the indifference with which he was welcomed his tract De principatibus by Lorenzo de Medici, who was dedicated and trusted the task of Italy's revival indifference contrasted with the acceptance that his work will have in the posterity, a highly controversial acceptance, praise and rejection, but never indifference.

Keywords: Machiavelli, State, power, Renaissance, science policy.

Palabras clave: Maquiavelo, Estado, poder, Renacimiento, ciencias políticas. 
En este 2013 se cumplen 500 años de De Principatibus (EI Príncipe) escrito por Nicolás Maquiavelo, que se constituirá desde entonces en obra fundacional de la ciencia política moderna. Una obra enormemente polémica, exaltada como apostrofada por seguidores $y$ adversarios. Ahora es necesaria su revisión, la cual nos revela la grandeza de su proyección y la actualidad de sus postulados.

La apreciación según la cual Maquiavelo (1469-1527) pone los fundamentos para la ciencia política moderna tiene una clara justificación. La época del Renacimiento, a la que pertenece, constituye un momento de grandes cambios y transformaciones que exige salidas o soluciones totalmente inéditas respecto de las formas anteriores de construcción del orden político. La disputa teológica y los conflictos religiosos que caracterizan al declinante medioevo demandan una nueva concepción de la construcción del orden y del poder político.

El largo proceso de conformación del absolutismo político bajo la figura de los estados nacionales, inicia con Maquiavelo. La política se presenta como actividad de construcción del poder en medio de fuertes tensiones; el enfrentamiento de poderes o de fuerzas contrastantes aparece como explosión de una materia magmática, que es la que conforma las relaciones intersubjetivas. La sociedad renacentista es laboratorio de creatividad artística y cultural. Desde la perspectiva de la articulación del poder político, presenta una imagen de alta conflictividad y desintegración de los ordenamientos políticos y religiosos; las condiciones socio históricas de la Italia renacentista terminarán por definir el paradigma de la política moderna como una lógica de permanente procesamiento de poder, que es en lo fundamental acumula- ción y reproducción de poder. Maquiavelo vivió con intensidad los conflictos políticos de su tiempo, fue actor e intérprete de su propia tragedia, la de la infructuosa búsqueda por hacer de la política el mejor instrumento para configurar la grandeza del Estado y de la república de Florencia, la cual se hallaba en el centro de fuegos cruzados.

Maquiavelo estudia las formas de producir acumular y reproducir poder político; en sus escritos, el poder aparece como capacidad y posibilidad de condicionar los comportamientos humanos, de ejercer sobre las personas operaciones y mecanismos de dominación y de subordinación. El Príncipe, su obra más conocida y famosa, se inscribe en este proyecto de construcción del Estado, en esta búsqueda para Italia de la regeneración del esplendor que una vez tuvo Roma como imperio, y que hoy, en el laboratorio florentino, podía emerger finalmente como República y ubicarse como Estado, con igual categoría y poder que las otras potencias de la época, Francia y España. Una tarea para la cual las condiciones no eran completamente propicias: la política en Italia aún se enredaba en las lógicas del poder y de las ambiciones de grupos y de líderes con escasa capacidad de visión estratégica y sin las agallas que exigía una tarea de este calibre. Una lógica altamente reversible e inestable que es reflejo de un entramado social, fuertemente comprometido en conflictos religiosos que devienen en enfrentamientos civiles, en un proceso de secularización creciente.

Con Maquiavelo se asiste a una formulación positiva del poder; éste existe más allá de cualquier consideración moral y es necesario; a través de él se expresan las fuer- 
zas sociales que dinamizan la vida de las colectividades y de los estados. La política, en la concepción maquiaveliana demuestra su función demiúrgica respecto de la sociedad; gracias a la política entendida como control y procesamiento del poder, se producen las condiciones para el encuentro inter-subjetivo, sólo la política crea sociedad.

La modernidad de Maquiavelo se expresa en su proyección estratégica; su intervención puntual en la política de Florencia está dirigida a la construcción y al control del poder político. El Estado como ordenamiento normativo, deviene destino y punto de llegada para toda política. Política como concentración y acumulación de poder en el Estado o como resistencia y neutralización de esa lógica de acumulación, como erosión de esa operación de centralización de fuerzas. En Maquiavelo, la política aparece bajo esta doble dimensión, lo que hace de sus posturas a menudo paradójicas; la política emerge como fuerza de agregación o como fuerza de disgregación, como tendencia de articulación de lo colectivo o como reclusión y defensa del apetito individual y privado. De aquí se deriva el carácter y el objeto de estudio de la ciencia política que Maquiavelo inaugura: el estudio de los instrumentos o mecanismos que promueven la organización del poder o del dominio de unos hombres sobre otros.

La originalidad de Maquiavelo, que lo proyecta como el primer pensador de la política moderna, consiste en establecer un vínculo fundacional entre el Estado como concentración de poder y el estudio de la conducta humana; cómo las personas se comportan de manera espontánea y cómo lo hacen bajo la presión de una determinada acción ejercida sobre ellas; en definitiva, cómo actúan y reaccionan frente a presiones externas, que en el caso de la política ya no son naturales sino subjetivas, eminentemente sociales. El estudio de la política es el estudio de la conducta humana atravesada por la lógica del poder, la cual garantiza la reproducción vital del sujeto social. La modernidad de Maquiavelo está en su postura secular en un contexto de fuertes tensiones religiosas; la política deja de ser la instrumentación en la tierra de un poder sobrenatural y pasa a ser la construcción de una obra humana por excelencia; tal cual acontece con la ciencia natural y experimental de Telesio o de Galileo; de igual forma, la ciencia de Maquiavelo es la experimentación de la mejor forma de organización de las relaciones interhumanas.

Maquiavelo no es un teórico en cuanto elaborador sistemático de conceptos; es un estudioso empírico a quien le interesa descubrir regularidades en el comportamiento humano sobre la base de la comparación entre la historia pasada y las condiciones de la política en la Florencia del renacimiento; pensador realista, interesado en no perderse en laberintos interpretativos y orientado más bien a captar el curso real de los acontecimientos sociales; a observar los acontecimientos, descubrir regularidades y elaborar generalizaciones o leyes explicativas acerca del comportamiento humano. Esta construcción de regularidades se presenta como elaboración de proto-conceptos que asumen la figura de consejos útiles para el buen gobierno; define, de esta manera, una característica metódica para la política moderna: racionalizar los comportamientos humanos en dirección a la construcción y reproducción del poder político. 
Dos fuentes alimentan las elaboraciones teóricas de Maquiavelo: el estudio del pasado, centrado en la reconstrucción de la historia romana, y el estudio de la formación del Estado en Florencia, una de las formas de organización política más avanzadas de su época. En Los discursos sobre la primera década de Tito Livio, seguramente su obra central, escrita entre 1513 y 1520, y publicada con posterioridad a su muerte, compara varios episodios resaltados por Tito Livio con acontecimientos extraídos de su historia presente, para de ahí establecer o deducir principios generales de política. En su obra más famosa, El Príncipe, editada en 1513, recoge verdaderas crónicas sobre el comportamiento de príncipes o aspirantes a serlo claves para la formación política de un Príncipe; el método es similar a Los discursos; establecer regularidades y comparaciones entre el pasado y el presente.

Estos dos libros, a los que se añade otro conjunto de obras, Del arte de la Guerra y su Historia de Florencia, delinean el objetivo puntual de Maquiavelo: definir una estrategia de regeneración de la política en Italia y de restauración del antiguo esplendor de la época romana; ésta recurrente orientación lo convierte, junto a Giambatista Vico, en uno de los iniciadores de las ciencias históricas. Maquiavelo funda su teoría política en el estudio del pasado, este acercamiento le permite elaborar conceptos que no son otra cosa que sistematizaciones de regularidades históricas.

La historia de Roma constituye el modelo desde donde mira su presente histórico; la utiliza como filtro analítico por el que atraviesan los acontecimientos de su época y adquieren significación; Roma aparece como un modelo normativo de sociedad y de cultura. En línea con todo el pensamiento del Renacimiento, Maquiavelo desarrolla una concepción cíclica de la historia: los acontecimientos históricos tienden a repetirse, lo cual delinea una cierta uniformidad e inmodificabilidad similar a la de la naturaleza humana. Siempre igual, la historia no se modifica ni cambia; como se actuaba en el pasado, se volverá a actuar en el presente $y$, por tanto, el comportamiento futuro puede ser predecible. A pesar de recurrir a la historia, Maquiavelo se mueve dentro de una concepción a-histórica del comportamiento político ${ }^{1}$. Esta característica de su pensamiento define una inclinación propedéutica; las experiencias del pasado se presentan como recurrentes, enseñan lo que es el presente y lo que será el futuro; el humano tiene que aprender del pasado para adecuar su comportamiento presente,

...y se conoce fácilmente -repite en los Discursos- para quien considera las cosas presentes y las antiguas, cómo en todas esas ciudades y en todos los pueblos, son los mismos deseos y los mismos humores, y cómo fueron siempre... De tal modo es fácil para quien considera con diligencia las cosas pasadas, prever en toda república las futuras, y procurar aquellos remedios que han sido usados por los antiguos, y no encontrando remedios ya usados, pensar en nuevos por la similitud de los accidentes.... ${ }^{2}$

\footnotetext{
1 “... suelen decir los hombres prudentes que quien quiere ver lo que debe ser, debe considerar lo que ha sido; porque todas las cosas del mundo en todo tiempo, pueden ser remitidas a los tiempos antiguos, porque siendo aquellas obras de los hombres que tuvieron y tiene las mismas pasiones, conviene por necesidad que surtan el mismo efecto". Discursos...III, XLII, p 496.

${ }^{2}$ Discursos..., I, XXXIX, p.222.
} 
El recurso a la historia no tiene como objetivo caracterizar una época o una sociedad, su función es pragmática, busca descubrir elementos de razonamiento útiles para la gestión de la política inmediata. La ciencia política de Maquiavelo es una ciencia ejemplificadora; los problemas y sus soluciones constituyen modelos puestos sobre la mesa del príncipe para que éste pueda tomar decisiones. Con Maquiavelo se inaugura una orientación que luego caracterizará a la ciencia política moderna: la investigación científica estará directamente funcionalizada a la organización y a la gestión de la sociedad y del poder. Todos los escritos de Maquiavelo podrían remitirse a una permanente ejemplificación, a la construcción de un anecdotario: ubicación de problemas-ejemplos que Maquiavelo saca de la historia romana, comparación de éstos con su historia presente, la de Florencia, y elaboración de conclusiones de carácter pragmático puestas al servicio de quien debe realizar el objetivo último de la ciencia política: la obtención y conservación del poder político.

Esta búsqueda de ejemplos, de regularidades, de hechos recurrentes, de situaciones y soluciones que se repiten, busca dar fundamento empírico a dos postulados básicos; el principio de la uniformidad de la naturaleza humana: tal como se comportaban las personas en el pasado, tal como reaccionaban frente a sus pasiones, de la misma manera se comportarán y reaccionarán en el futuro; y el principio de la igualdad esencial, la cual es entendida como igualdad de personalidad o de desarrollo de las capacidades humanas naturales; las personas son iguales en cuanto pertenecen a la especie humana, en cuanto poseen un mismo substrato natural.

\section{Naturaleza y libertad}

En esta determinación naturalista del hecho político, ¿qué puesto asigna Maquiavelo a la libertad? ¿Cuál es el espacio de libertad que queda para la voluntad humana? ¿Cómo se expresa la libertad del individuo y de la sociedad al interior de esta legalidad histórica? En la respuesta a estos interrogantes, Maquiavelo empieza a diseñar lo que será el concepto moderno de libertad. La libertad no es sinónimo de libre arbitrio, sino el resultado de una elección racional en la cual la voluntad empieza reconociéndose como limitada; la política en esta dirección se presenta como capacidad de adaptación inteligente a un curso de acontecimientos que difícilmente puede ser alterado por la voluntad humana. Movimiento inestable y de alta fluidez que caracteriza a las formas políticas, pero también a los 'humores' y a los comportamientos subjetivos, una libertad que con dificultad se levanta frente a un campo de complejidad constituido por el mundo de la pasionalidad, substrato natural de la reproducción subjetiva; no existe ninguna idea, acción o discurso que no esté determinado por esa realidad, natural, animal de los sujetos. La subterránea pasionalidad o animalidad del sujeto hace de los comportamientos y de las conductas humanas algo carente de orden y sentido y, por lo tanto, escasamente previsible. La pasionalidad se presenta como un conjunto confuso de reacciones a estímulos naturales que condicionan los actos y los comportamientos subjetivos; internas e intrínsecas determinaciones a la libertad del sujeto, que aparecen como 'espacio de lo irracional', limitada capacidad de previsión sobre los acontecimientos y sobre las propias reacciones, ausencia de sentido. La pasionalidad no es manejable, es una fuerza incon- 
trolable; toda posible introducción de orden y sentido choca con este residuo no manipulable, no racionalizable; espacio que no puede ser controlado, ni por el sujeto, ni por el Estado.

Este sustrato natural, pasional, hace que la historia sea imprevisible y establece límites a la expansión de la libertad; ésta sería alcanzable si pudiera liberarse de la presión que ésta ejerce sobre él, pero sus esfuerzos son vanos y su larvada presencia es fuente de incertidumbre; esta condición obliga al sujeto a generar respuestas igualmente pasionales, no suficientemente controlables ni previsibles en un diseño racional; la pasión define una precisa dimensión conductual. El comportamiento racional solamente aparecerá como dislocación o reversión de esta presión pasional; racionalidad y naturalidad se superponen, la racionalidad aparece como respuesta a la pasionalidad, pero también sustentada o proyectada por ella; se trata de una fuerza natural que relativiza a la razón y a sus posibilidades, y que define también el estatuto de relatividad de la política; ésta emerge o como expresión de la pura sobrevivencia humana, o es elaboración que proyecta lo humano hacia grados más altos de realización.

La naturaleza interior y exterior del hombre es el límite para la expansión de su libertad; idea central que estará presente también en Hegel, para quien la naturaleza ofrece resistencia al intento de dominación del sujeto; éste sólo puede engañarla, con el peligro de que en el momento que cree poder controlarla, aquella reacciona 'vengativamente' y recupera su dominio frente a él. Tanto en Maquiavelo como en Hobbes y Hegel, los comportamientos subjetivos tienen esta base; están constituidos por un sustrato de pasionalidad que predetermina la 'racionalidad' del comportamiento subjetivo: la naturaleza es indomable, por tanto, el control del cambio es relativo, se presenta bajo la imagen del azar, de lo fortuito, de lo impredecible; la razón, que al enfrentar estos obstáculos, se define por su capacidad de control y reacción frente a la determinación natural, no puede sino asumir la figura de la astucia.

Frente a los condicionamientos naturales, la libertad se presenta como razón y como astucia; define de esta manera un tipo de comportamiento gracias al cual el sujeto puede utilizar las fuerzas del objeto (que en este caso puede también ser la de otro sujeto) para lograr que éste responda a la necesidad de quien la promueve. La lógica del poder exige que cada actor lo acumule y lo reproduzca, y esta acumulación de poder aparece como utilización de las pasiones ajenas. Maquiavelo y Hegel se inscriben en la misma línea; la astucia es el estatuto de la racionalidad, es la parte activa que hace que el objeto se predisponga para la satisfacción del sujeto; predisposición que es del objeto, pero incentivada, activada por la astucia subjetiva de quien comanda la acción.

En Maquiavelo, la libertad, la astucia y la razón activan la política, permiten neutralizar todo condicionamiento y alcanzar el objetivo de toda política que es el poder. La política se identifica con el poder, es poder en su esencia más absoluta; al asimilarse a su forma racional como astucia, el poder hace que la disponibilidad de recursos y de objetivos giren sobre una plataforma extremadamente relativista; gracias a la intervención de la política, todo objeto 
o recurso puede estar dispuesto a una modificación de su estado natural o de su situación de partida. La política se abre a una multiplicidad de posibilidades, donde la diversa disposición de recursos y de objetivos juega un papel central, en una relativización al extremo de la conjunción entre medios y fines.

\section{Amoralidad, secularización y política}

El pensamiento de Maquiavelo está asociado a una imagen de amoralidad y de maldad. En el ámbito de una sociedad conflictivamente sujeta al poder temporal de la Iglesia, refleja el sentido de un pensamiento sumamente secular. Las condiciones del azar y de la fortuna caracterizan el devenir histórico; frente a ellas, la respuesta pasional del sujeto conduce a la construcción de una concepción negativa inderogable acerca de la naturaleza humana, que contrasta con el principio religioso según el cual la naturaleza humana está siempre dispuesta a la salvación mediante la redención de la culpa.

Maquiavelo, en un alarde de realismo, parte del supuesto de que el hombre, por naturaleza, se mueve hacia la destrucción del otro para garantizar su propia sobrevivencia; preanuncia la imagen hobbesiana del hombre como lobo del hombre, visión de la realidad cruda y descarnada que ha generado la leyenda de la malignidad de su pensamiento. La amoralidad de Maquiavelo está perfectamente fundada y constituye el resultado del relevamiento empírico de las condiciones del conflicto político de su época, pero representa también una asunción de valor; para alcanzar sus objetivos de reproducción, el hombre usa todos los medios que tiene a su disposición; para defender su interés, justifica cualquier medio; la reproducción del sujeto, la construcción y preservación de un mínimo de socialidad sin la cual éste perecería, constituye el fin último de la política.

En su forma germinal, la política es guerra y enfrentamiento. El Príncipe debe estar en capacidad de construir su poder mediante la anulación de los otros poderes; política y diplomacia se presentan como dos caras de una misma moneda, como arte de arreglar los conflictos o de preparar las mejores condiciones para el enfrentamiento y para la guerra; una funcionalidad alterna que tiene que ver con la presentación de los medios más adecuados para conseguir, mantener y reproducir el poder político. La consecución del poder en estos tres momentos supone el desarrollo de una política con distintas caras: concentración y acumulación de poder como resultado de la neutralización de la fuerza de impacto de los distintos poderes en pugna, conformación del mejor orden posible en cuanto articulación de una dimensión normativa, pero, además, aceptación de este poder y de este ordenamiento; estas tres dimensiones exigen de cambios en las conductas subjetivas; la política moderna solamente puede operar a través de la modificación de los comportamientos subjetivos.

Maquiavelo presenta a la política como el arte de enfrentar situaciones de alta inestabilidad y desarrolla una minuciosa y rigurosa racionalidad adaptable a condiciones conflictivas y cambiantes; en esta dirección, la política es arte más que ciencia; todos los argumentos y razones se detienen frente a lo imprevisible; la fortuna, como azar y reino de lo contingente, se hace presente para desbaratar cualquier proyecto concebido y construido de forma lógica. La política es capacidad de adapta- 
ción a las condiciones cambiantes de la fortuna, es diplomacia; pero también es respuesta al azar y a la fortuna, y puede detener o contener su fuerza disruptiva. En esta segunda acepción, la política es diseño racional y proyectualidad, la política en este caso, describe un preciso comportamiento subjetivo; detiene el juicio inmediato y da espacio al razonamiento. Diplomacia como arte de enfrentar a las fuerzas adversas, y política, como estrategia astuta de enfrentamiento al azar y a la contingencia de los eventos políticos, son recursos de cuya combinación dependerá el éxito de todo accionar político.

Muchos autores han evidenciado una gran capacidad de cambio de estilo en el discurso argumentativo de Maquiavelo, "no quiere hacer una obra de arte, ni adornar su discurso con cláusulas amplias y ampulosas; quiere despertar sabiduría política, no fineza literaria, convencer, no hacerse aplaudir, mover fuertemente el ánimo, no aplacarlo en la elegancia del estilo" ${ }^{3}$ Maquiavelo alterna una inteligente comunicación entre dos planos: el de la política inmediata, atenta a las formas de impacto, y el de la política proyectual, de más largo respiro; combina ágilmente un discurso dialectal con un discurso reflexivo racional.

Maquiavelo realiza una distinción fundamental entre la pequeña y la gran política; la primera es la política de todos los días, coyuntural, real política; su pleno control debería conducir, a la realización de la segunda, la gran política, cuyo objetivo último es la constitución del Estado entendido como potenciación de la vida social. La

\footnotetext{
${ }^{3}$ Chabod, Introducción a /I Príncipe, de N.
} Machiavelli, Torino, 1977, p. XXXV. pequeña política en función de la gran política, de allí su relativización extrema: de acuerdo a las circunstancias de la época y del momento, bien puede ser útil una $u$ otra forma política. Las formas políticas monárquica, aristocrática o democráticaconstituyen dimensiones instrumentales que permiten la consecución del poder, entendido como potenciación de las capacidades reproductivas de los sujetos; como instrumentos, que deben adaptarse a las condiciones efectivas de circulación y de reproducción del poder.

Maquiavelo establece una cierta legalidad remitible más al comportamiento político, a la actividad subjetiva, que a una determinada objetividad de la historia; cuando la sociedad se presenta disgregada y el poder disperso, la política deberá orientarse hacia la constitución de un poder fuerte y centralizado; de igual manera, cuando la sociedad se encuentra estructurada políticamente y el poder centralizado, la política deberá orientarse más hacia su desconcentración y distribución. Para Maquiavelo, entonces, moverse dentro del ámbito de la pequeña política y de las formas políticas, constituye una actividad instrumental necesaria para el logro del objetivo último: favorecer el poder, la potencia y la grandeza del Estado.

Surge, entonces, el sentido de esta dimensión estratégica: favorecer el poder y la grandeza del Estado; sin embargo, ¿por qué hacerlo? Maquiavelo, preanunciando a Hegel, diría que sólo el Estado permite realizar la libertad de los sujetos, y constituye el requisito de orden necesario para que éste pueda realizar su libertad y garantizar su reproducción; el Estado aparece entonces como marco o cuadro de regula- 
ciones necesario para la introducción y reproducción del orden, pero también como realización de un pueblo y una nación. En Maquiavelo encontramos las ideas germinales de lo que será la teoría del Estado nacional: aparato burocrático, en cuanto sistema de regulaciones, pero no abstraído de las determinaciones concretas de un pueblo, de una historia y de una nación. Esta tesis de Maquiavelo se constituirá luego en un argumento central para la definición del político moderno: éste sabe percibir el curso de la historia y adecuar sus acciones al ritmo de ese curso, percibe las determinaciones reales e inscribe su accionar en ellas.

El político en Maquiavelo se distingue tajantemente del ideólogo, mientras el primero mide sus acciones a partir de las determinaciones y posibilidades históricas específicas, el segundo trata de borrar esas determinaciones históricas y proponer algo que está por fuera de esa lógica natural. En El Príncipe, Maquiavelo plantea esta tesis de la siguiente manera, "Es feliz aquel que pone de acuerdo su modo de proceder con las cualidades de su tiempo, mientras es infeliz aquel que con el proceder del tiempo se encuentra en conflicto". Esta concepción del político, como quien sabe conectarse con las fuerzas reales de la historia, será posteriormente retomada por Hegel, quien planteará la diferencia del hombre político y del ideólogo en términos sustancialmente análogos; Hegel lo presenta bajo la figura del "alma bella": el ideólogo se mueve en el deber ser cuya realización contrasta con las determinaciones históricas de su tiempo; el político, en cambio, inscribe su accionar en las determinaciones de su tiempo, su racionalidad es pragmática y no especulativa.
Una combinación de pragmatismo y visión estratégica que Maquiavelo no encontró en los líderes de su tiempo; la tragedia de Maquiavelo no consistió solamente en su aislamiento de las lógicas del poder, en su dificultad por incidir decisivamente en el curso político de la Florencia de su época, su mayor tragedia residió en la indiferencia con la cual fue acogido su opúsculo De principatibus por Lorenzo de Medici a quien estaba dedicado y en quien confiaba la tarea del resurgimiento de Italia; indiferencia que contrastará con la aceptación que su obra tendrá en la posteridad, una aceptación enormemente polémica, de elogio y rechazo, pero en ningún caso de indiferencia. 